\title{
A educação médica em construção: análise das novas diretrizes curriculares nacionais do curso de Medicina em relação às expectativas de estudantes de uma instituição de ensino superior
}

\author{
Maria Alexandra de Carvalho Meirelles
}

\begin{abstract}
Resumo
Considerando a importância do papel do médico na sociedade, torna-se cada vez mais necessário discutir a formação desse profissional de saúde a partir das dimensões humana, política, técnica e conceitual, para além da perspectiva biologicista centrada em conteúdos acadêmicos. Nesse sentido, o presente trabalho, resultado de um projeto de iniciação científica,tem por objetivo analisar as novas Diretrizes Curriculares Nacionais (DCNs) do Curso de Medicina (Resolução n³, de 20 de junho de 2014)identificando as principais mudanças em relação às DCNs anteriores (Resolução $\mathrm{N}^{\circ}$ 4, de 07 de novembro de 2001).A partir da revisão em periódicos nacionais, até o momento (junho de 2016) não foram localizadas publicações sobre as novas DCNs, apenas sobre as Diretrizes de 2001, o que justifica a relevância deste estudo. Quanto à metodologia, a pesquisa classifica-se como descritiva e explicativa, sendo a abordagem qualitativa pela análise documental. Os resultados são apresentados de forma comparativa considerando os seguintes aspectos das duas Diretrizes: 1) Perfil do formando: as DCNs de 2014 complementam as Diretrizes de 2001 e enfatizam o caráter humanístico do futuro profissional visando sempre o respeito aos direitos humanos e as diversas culturas. 2) Competências e habilidades gerais: nas DCNs de 2014 as competências gerais são divididas em três áreas: I Atenção Integral a Saúde, II Educação em Saúde e III Gestão em saúde. Essa nova divisão em relação ao documento de 2001, tem o objetivo de formar profissionais que sejam capazes de liderar a equipe multidisciplinar, principalmente no âmbito da atenção primária e, que exerçam também o papel de educadores em relação aos seus pacientes. 3) Competências e habilidades específicas: o conjunto das competências específicas abordadas nas DCNs de 2014 reforça a necessidade de uma atuação integral que considere o paciente em todos os aspectos sociais, históricos e emocionais que possam interferir no processo de saúde-doença. Essas novas habilidades podem ser consideradas um avanço em relação às Diretrizes de 2001, pois direcionam de forma particular as características que devem ser encontradas ao final da graduação. No entanto um aspecto importante, como a saúde do próprio discente, que era citada no artigo $5^{\circ}$ (item XVIII) da resolução de 2001, deixou de ser abordada no novo documento. 4) Projeto político-pedagógico e processo de ensino: com as DCNs de 2014, o currículo foi ampliado e novas disciplinas das áreas de ciências humanas e sociais foram incluídas. Conclui-se que as novas DCNs(2014) vieram para ampliar as Diretrizes anteriores (2001) contemplando seus aspectos mais relevantes no que diz respeito as habilidades médicas que devem ser adquiridas ao longo da graduação. Contudo, a falta de pesquisas que abordem a relação do discente com sua rotina e a sua própria saúde pode ser considerada uma fragilidade das novas DCNs, abrindo-se assim um espaço para uma possível discussão sobre a qualidade do ensino e o bem-estar discente.
\end{abstract}

Descritores: Educação médica; SUS; Medicina 